\title{
The Research to the Influential Factors of China's Urban Income Level of Low-income Groups
}

\author{
Zhe Zhou \\ Qingdao University, Qingdao, China \\ zhouzheyxyx@163.com
}

Keywords: Low - income group; Income level; Panel co-integration

\begin{abstract}
In recent years, China's economic development has made great achievements, but the gap between the rich and the poor is widening. Low-income groups because of socio-economic reasons, low income levels, so facing greater pressure on life, they need to get social attention and support. Solving the problem of low - income groups is related to the long - term stable operation of the economy and the harmonious development of society. To study the income problem of low-income groups, we must analyze the income factors of low-income groups. In this paper, the panel data of urban low - income groups in 30 provinces and cities (except Tibet) from 2001 to 2015 were analyzed by panel analysis. The analysis shows that GDP, employment, education investment and social security investment have a significant effect on the income level of low - income groups. Finally, on the basis of the above conclusions, we give the policy suggestions to increase the income of low-income groups.
\end{abstract}

\section{Introduction}

With the rapid development of China's economic and social, people's standard of living has improved significantly. Social gap between rich and poor, meanwhile, it still exists, with prices rising rapidly, facing the life pressure is more and more of the low-income group. So this group need to get the attention of the whole society. In 2015, the Chinese urban low-income groups, household annual per capita disposable income of 12231 yuan, with per capita 65082 yuan, the highest income households group significantly larger gap between the rich and poor. With the deepening of the reform in cities and towns, the income of low-income groups problems need to be resolved, improve the income level of low-income groups, narrowing the low-income groups the size of the action is urgently needed.

In recent years, scholars from the income of low-income status, the causes for the low income and low income policy in these three aspects, has carried on the detailed and effective research. Zhu Shihong (1999) think that macroeconomic factors such as economic structure impact is one of the important factors gave rise to the low-income groups; Li shi $(2002,2002)$ that individual micro characteristics of the low-income group is the main cause of its produce. National bureau of statistics (NBS) group (2002) study showed that $70 \%$ of low-income people for junior high school the following level cultural degree, and low-income people in town for junior high school education degree below 49\%. Handful of (2006) system elaborated the definition of the low-income group rules and the size distribution and the analysis of the causes, think that we should increase employment, establish and improve the social security system and the development of education and other aspects to promote the low-income groups' income; Yun-shan Yang (2006) from the optimization of the income distribution relations, implement a proactive employment policy, and establish long-term effective mechanism of increasing Angle analysis of the main way to increase the income level of low-income people; Chen Naping (2012) through analysis income vector autoregressive model, proper decomposition of the influence factors of low-income groups, how to improve the income level of low-income group related policy. Cao yong, etc (2016) studied the urban low-income groups in inflation to bear ability, found that the influence of the rising prices for low-income groups is greater than the impact on middle-income groups; Subentry income of low-income groups to withstand strong inflation are profit-making and transfer income, and 
moderate income group is the business and property income. Chang Xiang Holland (2016) put forward the reform way of training, innovation measures of employment, support policies and related measures and Suggestions to improve the living conditions of urban low-income groups.

The income level of low-income groups influence factors can promote the low-income groups' income policy has a good guiding role. In 30 provinces, cities and towns on the mainland (except xinjiang) low-income groups, this paper analyze the factors affecting income level, through the establishment of panel data model to carry on the empirical analysis, from the macro economic and micro individual factors are comprehensively analyzed the factors lead to the low level of income of urban low-income groups, to improve the income level of low-income group related policy to provide the reference.

\section{The Definition and Influencing Factors of Low-income Groups}

Currently on low-income groups defined there are mainly two standard first is relatively standard: according to the income and then according to the proportion of low-income groups. For example, will be ordered from low to high per capita income, those in the lowest $10 \%$ or $20 \%$ of the population is defined as the low-income groups; The second is the absolute standard: overall average income of a certain proportion as low-income standards; Local common standard of poverty line, for example, poverty line can meet the needs of subsistence and income level of low-income group is below the poverty line, can also be the poverty line according to certain proportion, expand expanded to $150 \%$.

In this paper, due to the data processing and the empirical analysis to consider using relative standard. Namely USES the statistical yearbook of provinces and cities, processing method, income from low to high order according to the number of average into seven groups, namely the lowest, low-income households, middle-class households, middle-income households, the average household, high income families, and the highest. Therefore, the above minimum and low-income households in low-income groups in this article.

There are many factors influencing the income level of low-income group, this paper from two aspects: economic factors, social factors are analyzed.

\section{Economic Factors}

The Economic Development and Economic Structure. Regional economic development and income level of low-income groups are closely linked, low-income groups' income is sustained growth in regional economy cannot leave. From the point of data, fast economic development of regional income level of low-income groups to be significantly higher than the economy less developed areas. In recent years, due to the European and American economy cooling and the influence of its own domestic economic structure adjustment, China's economic growth slowed, but still promote residents' income is an important economic growth engine.

Many areas to develop the labor-intensive industries in the past, to solve the problem of employment of many people, but with the transformation and upgrading of industrial structure, some of the labor-intensive industry is bound to be laid-off employees. A few years ago because of the sharp appreciation of the renminbi rapid, many by labor cost advantage of export enterprises face collapse and a large number of laid-off workers, so that the rise in the number of low-income groups.

The Employment. Unemployment has a more significant impact on low-income groups, laid-off workers accounted for a large proportion of low-income groups, a lot of come off sentry duty the unemployed have not benefit from the re-employment policy. Employment guidance, the government management system is not perfect enough policy, at the same time, social lack of authority, focus on labor intermediary service organizations of workers providing services such as consulting, arbitration. Other non-standard operation, the Labour market and unit of choose and employ persons exist some enterprises in the use of laid-off workers, pay low wages, and not for them to handle social insurance, etc. [17] reduced unemployment rate can reduce the number of 
laid-off people, improve the income level of low-income groups directly.

\section{Social Factors}

The Level of Education. Data show that received a certain education and have a certain skill of a person's ability to generate income is far higher than Wen Mangzhe. In recent years despite the bigger of the two countries in the aspect of education investment, but in some remote areas education conditions are still not optimistic. The lower level of education they have, the less skills, then obtain the smaller the possibility of high income job, this leads to the higher the probability of falling into poverty. Therefore improve the level of culture helps to income of the low-income group.

Social Security. To high prices in the present case, some relevant policies of social security system such as raising the minimum life to ensure standard, expand pension coverage, etc., to improve the level of low-income groups related welfare plays an important role, can guarantee the basic life and maintenance of urban low-income families, narrow the income gap in society. So the increase of their social welfare has a more direct impact on income level of low-income groups.

Other Social Factors. Lead to some lower family income level for some special social factors, such as for some disease caused by accidents, residues, etc. Some families losing major source of labor and economy because these reasons, unable to normal life. To solve this problem need to regional medical security system and the improvement of the social assistance system better.

\section{The Empirical Analysis}

Variable Selection and Data Sources. In this paper, the research object is the mainland of 30 provinces and municipalities directly under the central government (except Tibet), urban low-income groups all use of sample data from China statistical yearbook, statistical yearbook, various provinces and cities were taken from 2001 to 2015, a total of 15 years in 30 provinces panel data of the samples. At the same time in terms of defining the standard of the low-income group adopted the relative standards, specific measure is reference to the provincial statistical yearbook seven group division method, to the lowest income households and low-income group delimit urban low-income groups. Considering the number of the lowest income groups and low-income households group were $10 \%$ proportion, so will be 30 provinces and cities in 2001-2015 (except Tibet) of urban residents per capita cash income of the lowest income groups, and the weighted average per capita disposable income of the low-income group, as the income of low-income groups.

In terms of variable selection, this article chooses the level of regional economic development, unemployment, education investment, social security into four indicators. Of regional economic development level in the provincial GDP, employment by the provincial urban registered unemployment, education investment by the provincial education spending, investment of social security with the provincial regional government spending on social security fees.

Table 1 variable selection list

\begin{tabular}{cc}
\hline $\begin{array}{c}\text { Variable } \\
\text { meaning }\end{array}$ & implication \\
\hline $\mathrm{I}$ & low-income groups per capita disposable income (yuan) \\
$\mathrm{G}$ & GDP (one hundred million yuan) \\
$\mathrm{S}$ & Registered urban unemployment (ten thousand) \\
$\mathrm{J}$ & Education funds (\$one hundred million) \\
$\mathrm{F}$ & Social security expenditure (one hundred million yuan) \\
\hline
\end{tabular}




\section{Model Test and Estimate}

The Model Set. General panel model for single equation.

$$
\begin{gathered}
y_{i t}=\alpha_{i}+\mathbf{x}_{i}^{\prime} \boldsymbol{\beta}_{i}+u_{i t} \\
\mathrm{i}=1,2, \ldots, \mathrm{N}, \quad \mathrm{t}=1,2, \ldots, \mathrm{T}
\end{gathered}
$$

Where $\mathrm{N}$ is the number of members, said section $\mathrm{T}$ for each section are members of the observation period, total parameter model of constant term, said corresponds to explain the variable vector $\mathrm{k} \times 1$ dimensional vector, $\mathrm{k}$ said explanation variable number. Random error term are independent of each other, and meet with zero mean and variance of $\mathrm{u} 2$ 's assumptions.

Due to large sample part of the index data, can consider to take logarithms. On the one hand, make the data smoothing, eliminate the effects of different measurement unit; On the other hand can abate the heteroscedasticity model data. Therefore the variable I, G, S, J, F take logarithm for $\operatorname{lnI}$, $\operatorname{lnG}, \ln S, \operatorname{lnJ}, \ln F$. Thus the following regression equation is established.

$$
L n I_{i t}=a_{i}+b_{i} L n G_{i t}+c_{i} L n S_{i t}+d_{i} L n J_{i t}+e_{i} L n F_{i t}+\mu_{i t}
$$

The Panel Unit Root Test. Considering the economic study many sequences are usually not smooth, if in accordance with the traditional method of econometric analysis directly to regression equation, then there will be a spurious regression phenomenon, econometric analysis results will be meaningless. So for each variable must be smooth panel unit root test to verify wheCommon panel unit root test with Fisher - ADF test (Maddala and Wu, 1999; Choi, 2001), LLC inspection (Levin, Lin and Chu, 2002), the IPS test (Im, Pesaran and Shin, 2003), inspection, etc., this paper USES the LLC inspection, IPS, ADF - Fisher stationarity test to verify the panel data. The results in table 4.2:ther the data.

Table 2 panel unit root test results

\begin{tabular}{cccc}
\hline $\begin{array}{c}\text { Variable } \\
\text { meaning }\end{array}$ & LLC & IPS & ADF-Fisher \\
\hline $\mathrm{I}$ & $19.5082(1.0000)$ & $22.5946(1.0000)$ & $0.15943(1.0000)$ \\
$\mathrm{G}$ & $25.6796(1.0000)$ & $28.2666(1.0000)$ & $0.01298(1.0000)$ \\
$\mathrm{S}$ & $3.99224(1.0000)$ & $-2.00728(0.0424)$ & $16.2033(1.0000)$ \\
$\mathrm{J}$ & $37.1837(1.0000)$ & $36.8018(1.0000)$ & $0.58193(1.0000)$ \\
$\mathrm{F}$ & $47.2843(1.0000)$ & $43.7286(1.0000)$ & $0.33685(1.0000)$ \\
$\mathrm{dI}$ & $-9.86052(0.0000)$ & $-3.84090(0.0001)$ & $136.944(0.0000)$ \\
$\mathrm{dG}$ & $-21.4871(0.0000)$ & $-6.88919(0.0000)$ & $209.652(0.0000)$ \\
$\mathrm{dS}$ & $-14.4195(0.0000)$ & $-6.00977(0.0000)$ & $162.741(0.0000)$ \\
$\mathrm{dJ}$ & $-8.55382(0.0000)$ & $-1.87583(0.0302)$ & $89.1438(0.0000)$ \\
$\mathrm{dF}$ & $-7.67090(0.0000)$ & $-2.11794(0.0131)$ & $80.7531(0.0258)$ \\
\hline
\end{tabular}

Noted Said Difference, $\mathbf{P}$ Values are Shown in Brackets. Test results show that the five variables of the original data are obvious unit root, but after the first order difference is smooth, so 
the five variables are first order single whole.

The Co-integration Test. Discovered by stationarity test variables are not smooth, but variables exist with order list, so you can guess the variable there may be a long-term and stable relationship between the co-integration relationship, that is to say, although the variables are stationary, but their linear combination can be smooth, so model will still be able to explain and analysis and economic significance.

Here in this paper using the panel data of Fisher (combined Johansen) inspection.

Table 3 the panel co-integration test results

\begin{tabular}{ccc}
\hline $\begin{array}{c}\text { The null } \\
\text { hypothesis }\end{array}$ & $\begin{array}{c}\text { Fisher joint statistics } \\
(\mathrm{p} \text { value })\end{array}$ & $\begin{array}{c}\text { Fisher }(\mathrm{p} \text { value }) \text { - Max statistics } \\
(\mathrm{p} \text { value })\end{array}$ \\
\hline $\begin{array}{c}\text { 0 collaborators } \\
\text { whole vector } \\
\begin{array}{c}\text { At least } 1 \\
\text { collaborators } \\
\text { whole vector }\end{array}\end{array}$ & $248.8(0.0000)^{*}$ & $204.0(0.0000)^{*}$ \\
\hline
\end{tabular}

Note: with "*" said under the significance level of 5\% reject the null hypothesis and accept the alternative hypothesis.

From the point of inspection results after the table 4.3, cointegration test rejected the variable I, S, $\mathrm{J}, \mathrm{F}$ and $\mathrm{G}$ null hypothesis does not exist co-integration relationship, income level and GDP, unemployment, education investment, social security costs, etc. There are at least one collaborators integral relationship between variables.

The Regression Model with Explanation. Panel model generally has three forms: estimation model

$$
y_{i t}=\alpha+\mathbf{x}_{i}^{\prime} \boldsymbol{\beta}+u_{i t}
$$

No influence of the individual constant coefficient model.

variable intercept model

$$
y_{i t}=\alpha_{i}+\mathbf{x}_{i}^{\prime} \boldsymbol{\beta}+u_{i t}
$$

Individual impact on the cross section is what is the constant coefficient of the model.

the variable coefficient of the model

$$
y_{i t}=\alpha_{i}+\mathbf{x}_{i}^{\prime} \boldsymbol{\beta}_{i}+u_{i t}
$$

This is already exist individual effect and economic structure change of variable coefficient model.

First of all, try to establish unified hybrid estimation panel model, estimates that the results are as follows

$$
\begin{aligned}
& L n I_{i t}=6.0304+0.1874 L n G_{i t}-0.5089 L n S_{i t}+0.0909 L n J_{i t}+0.3854 L n F_{i t}+\mu_{i t} \\
& (34.74) \quad(3.66) \quad(-18.74) \quad(2.00)
\end{aligned}
$$

$$
\mathrm{R} 2=0.7197 \quad \mathrm{~F}=403.37 \quad \mathrm{DW}=0.1991
$$

The above regression model coefficient of various factors are significant, the $\mathrm{F}$ value is very high, but smaller values of the DW is the related phenomenon, and the equation of fitting degree is not high. This model may not be suitable for, also cannot fully explain the income and the relationship between various influencing factors, can consider to use other model. In order to determine which use a panel model, using analysis of covariance test here. Principle is as follows:

Two assumptions: 
$\mathrm{H} 1: \boldsymbol{\beta}_{1}=\boldsymbol{\beta}_{2}=\cdots=\boldsymbol{\beta}_{N}$

$\mathrm{H} 2: \alpha_{1}=\alpha_{2}=\cdots=\alpha_{N}$

$\boldsymbol{\beta}_{1}=\boldsymbol{\beta}_{2}=\cdots=\boldsymbol{\beta}_{N}$

If accepted hypothesis $\mathrm{H} 2$ can think model for constant parameter model, the need for further test. If it refuses to hypothesis $\mathrm{H} 2$, need to test hypotheses H1. If you accept H1, see model for variable intercept model, whereas refused to $\mathrm{H} 1$, see model for variable parameter model.

F statistics of hypothesis test are as follows:

$$
\begin{aligned}
& F_{1}=\frac{\left(S_{2}-S_{1}\right) /[(N-1) k]}{S_{1} /(N T-N(k+1))} \sim F[(N-1) k, N(T-k-1)] \\
& F_{2}=\frac{\left(S_{3}-S_{1}\right) /[(N-1)(k+1)]}{S_{1} /(N T-N(k+1))} \sim F[(N-1)(k+1), N(T-k-1)]
\end{aligned}
$$

Which is suitable for variable parameter model of the sum of squared residuals $S 1, S 2$ is variable intercept model residual sum of squares of S3 for constant parameter model of the sum of squared residuals.

According to the type calculation on $\mathrm{F} 1=0.3966, \mathrm{~F} 2=35.25$, look-up table under the significance level of 5\%.

Alpha $1(116210)=1.32$, F F alpha $2(135210)=1.36$ the conclusion: refused to H2, accept H1, which shall establish variable intercept model.

Considering the variable intercept model is fixed and random effect two kinds, the following test to verify against Hausman. The random effect model is established first, and then test whether refused to the original assumption. Inspection results are as follows:

Table 4 Hausman test results

\begin{tabular}{ccc}
\hline Chi-Sq.Statistic & Chi-Sq. d.f. & Prob. \\
\hline 178.121054 & 4 & 0.0000 \\
\hline
\end{tabular}

By the test results come to the conclusion that can build individual variable intercept fixed effect panel model. The model is as follows,

$$
\begin{aligned}
& \operatorname{LnI_{it}}=2.8572+0.5489 L n G_{i t}-0.1530 \operatorname{LnS}_{i t}+0.0540 L n J_{i t}+0.1579 L n F_{i t}+\mu_{i t} \\
& (9.65) \quad(-2.37)
\end{aligned}
$$

$\mathrm{R}_{2}=0.87 \quad \mathrm{~F}=362.36 \quad \mathrm{DW}=1.86$

Provinces intercept in the following table: 
Table 5 provinces intercept estimates

\begin{tabular}{cccccc}
\hline region & interceptC & region & interceptC & region & interceptC \\
\hline Beijing & 0.275625 & Zhejiang & -0.243636 & hainan & 0.969864 \\
Tianjing & 0.375418 & Anhui & -0.094166 & chongqing & 0.348039 \\
Hebei & -0.323144 & fujian & 0.044455 & sichuan & -0.479502 \\
Shanxi & -0.083663 & jiangxi & 0.110252 & guizhou & 0.307330 \\
Neimenggu & 0.090725 & shandong & -0.710436 & yunnan & 0.107034 \\
Liaoning & -0.447880 & henan & -0.576442 & shanxi & -0.013420 \\
Jilin & 0.098974 & hubei & -0.323144 & gansu & 0.271275 \\
Heilongjian & -0.340511 & hunan & -0.240561 & qinghai & 1.104029 \\
g & 0.118564 & guangdong & -0.861952 & ningxia & 1.216395 \\
Shanghai & -0.830269 & guangxi & 0.047462 & xinjiang & 0.083284 \\
Jiangsu & & & &
\end{tabular}

Seeing from the panel model, variable intercept model and mixed panel model in fitting before had the very big enhancement, variable coefficient is very significant, has a high $\mathrm{F}$ value, at the same time also more economic significance and realistic significance.

\section{Conclusion}

From the point of the model results, economic development level, unemployment, education, social security, the four factors on the income level of low-income groups. Economic development level is the most important related to the income level of low-income groups, economic development faster GDP of the low-income groups income is obviously higher than less developed areas, and the GDP of its income groups influence coefficient up to 0.5489 , at this point the empirical analysis results are in good agreement with the actual situation; The index of social security expenditure on the impact on the income level of low-income groups also occupy the important position, since welfare costs including pensions, to lose their jobs or lose labor ability or retired that part of the income of the low-income group security plays a very important role, although countries and regions in recent years, the government in increasing spending on social security, but also need to expand on coverage; Employment and income level of low-income groups also has an important connection, influence coefficient is 0.1530; About education factors, the influence factors in the model is small, it is because the education investment is a long-term project, it is hard to see the obvious effect in the short term.

From regional point of view, such as Beijing, Shanghai, zhejiang some of the more developed regions economic income level of low-income groups than in the western regions such as guizhou, gansu, qinghai, can be understood as a productivity differences will lead to the general level of income. Other developed areas of investment in education, social security investment are significantly higher than the economy less developed areas, it is also the important cause of regional income level of low-income group differences

Model estimation results show that at the same time, under the assumption that under the condition of other variables constant, when GDP increased by $1 \%$, a $0.5489 \%$ increase in income of urban low-income groups; Under the condition of invariable assumes that other variables, when the region registered urban unemployment by $1 \%$, a $0.1530 \%$ increase in income of urban low-income groups; In the case of assuming that other variables constant, when the region education investment spending increased by $1 \%$, a $0.0540 \%$ increase in income of urban low-income groups; Assume that 
other variables constant, when the area of social security costs increased by $1 \%$, a $0.1579 \%$ increase in income of urban low-income groups.

In the practical significance, such four factors have significant effect on low-income groups. GDP growth directly reflects the economic growth, and the economic environment is closely linked, can directly promote the rapid development of economy and society, and also inevitably leads to low-income groups' income; Unemployment rate can reduce obviously to reduce the scale of low-income groups, many of the unemployed to find work, and make it get a qualitative change; The increase of education investment can give more students on the school security, poor areas to knowledge change destiny. At the same time, more skills training can bring the unemployed again obtain employment opportunities; And social security costs are a major source of social vulnerable groups, reasonable plan as a whole and arrangement of social security to promote social harmony has the influence, which is closely linked with the further widening of the gap between rich and poor, some social underlying life more difficult, the increase in welfare costs to improve its life is especially important.

\section{Policy Suggestions}

Above the empirical analysis results show that the regional GDP, employment, investment in education, social security investment and the income level of low-income groups have a certain relationship, including GDP, employment, social security into three factors that affect income level is more significant. But that is only using the results of data analysis, has some limitations, in real life but also to take corresponding policies according to the specific situation to make income urban low-income groups. Finally, the paper USES the results of empirical analysis, in combination with the practical situation of society puts forward some policy Suggestions from the following four aspects:

One is to speed up the pace of the economy. On the premise of guarantee the stability of the economic development, increase the social capital investment, improve the economic development achievements in the popularization of the whole society, create more jobs makes the low-income families can also share in the benefits. The government can encourage some emerging investment, which is beneficial to speed up the construction of city. At the same time we need to promote economic adjustment of industrial structure, enlarge the proportion of the tertiary industry, encourage high-tech high benefit enterprises, safeguard the legitimate interests of the employees. As far as possible avoid industry recession or business failures, such can weaken the impact of urban low-income jobs to apply for a job.

The second is to promote employment and reemployment. Employment is solving the problem of urban unemployed workers and rural surplus labor force is one of the most effective measures. So the government must insist for a long time and promote employment policies, efforts to seek and broadening the employment channels, the current unemployment to provide more jobs for the society.

Three is the implementation of social security. To speed up the reform of the social security system. The government as soon as possible to establish and perfect the social security system of whole society, will the current protection implement every policy of the low-income group. Try to make every worker endowment insurance and unemployment insurance, avoid the generation of new low-income groups.

Fourth, attaches great importance to the education and training. In terms of education, education institutions and the society should ensure the popularization of compulsory education in urban and rural areas, in time for cost reduction and help poor people. Only improve the level of low-income groups of education, improve their cultural level, to make it a better employment and revenue enhancement.

\section{References}

[1] Am Paro, Human Capital Inequality, Life Expectancy and Economic Growth[J]. TheEconomic 
[2] Ben-David, Economic growth and its effect on income distribution [J],Journal of Economic Studiess, 2007,34(1):42-58.

[3] Noguera M, Siscartb M, Trade raises income: a precise and robust result. Journal of

[4] International Economics[J], 2005, 65: 447 460.

[5] B.K Chen, Lin, Development strategy, urbanization and China's income gap between urban and rural areas [J]. Chinese academy of social sciences, 2013, 81:81-102 +206.

[6] S.H Zhu, The current solution to the problem of urban low-income residents life difficult work and countermeasures [J]. Journal of macroeconomic research, 1999, 11:42-44.

[7] Peter, X.G Wu, Income inequality and distributive justice: the transition period of China's urban residents fairness of an empirical analysis [J]. Chinese academy of social sciences, 2012 01: + 207 114-128.

[8] B.Q Li, Our country residents' income growth and its influencing factors research [D], Wuhan: huazhong university of science and technology, 2007.

[9] Handful. Chinese urban low-income groups research review [J]. Journal of population and economy, 2006, 11:54-59.

[10] Anderson, ms, S Li, Urban Labour market structure changes and income inequality: 1989 2009 [J]. Management world, 2013,01:45 to $55+187$.

[11] X.H Ma, For low income earners and the degree of income inequality between high earners analysis [J]. Management world, 2003,09: + 94-156. 62-67.

[12] S.D Fan, Chinese labor mobility and the income gap of kuznets effect research [J]. Journal of economic review, 2011, 2011:44-53.

[13] S Li, C.L Luo, China's income gap is how much? - on fixed sample structure deviation attempts [J]. Journal of economic studies, 2011, 68:68-79.

[14] Q.C He, Tax, income inequality and the endogenous economic growth [J]. Journal of economic studies, 2012, 11:4-14.

[15] Y Cao, X.B Luo, Urban low-income groups in inflation to bear ability research - based on the macro to the empirical analysis of jiangxi [J]. Journal of academia, 2016. (01) : 237-245 + 328 .

[16]X Chang, Improve the living conditions of urban low-income groups [J]. Journal of macroeconomic management, 2016, (8) : 62-64. 